\title{
Non-Puerperal Uterin Inversion Caused by Myoma of the Uterus
}

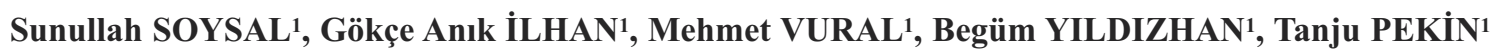 \\ Istanbul, Turkey

\begin{abstract}
Non puerperal uterine inversion is a rare event and mostly caused by uterine myomas. Herein a case of uterine inversion caused by myoma protruding through vagina is presented. Uterine inversion should be considered in patients with uterine mass protruding to vagina.
\end{abstract}

Keywords: Uterine inversion, Myoma uteri

Gynecol Obstet Reprod Med 2016;22:40-41

\section{Introduction}

Uterine inversion is a rare event. It generally occurs immediately in early postpartum period. Non puerperal inversion is even rarer and mostly seen in cases of myomas. Bleeding, vaginal mass and pain are the common complaints of the patients with uterine inversion. ${ }^{1}$ Uterine inversion may not be diagnosed during examination. Impalpable fundus and non visible cervix are the determining findings of inversion..$^{2-3}$ Hysterectomy may be inevitable for treatment of non puerperal uterine inversions.

\section{Case Report}

55 year old woman G3P3 admitted to our clinic with a complaint of vaginal bleeding of 3-4 peds per day. She had no remarkable medical and surgical history. Her systemic examination did not reveal any findings. Before admission to our hospital although 7 units of eritrosit suspension was transfused to patient in a health facility, the hemoglobin level was still $8.7 \mathrm{mg} / \mathrm{dL}$. In pelvic examination $7 \mathrm{~cm}$ of mass, protruding to the vagina was detected. The cervix was not visualized. In transvaginal ultrasound examination $68 \times 57 \mathrm{~mm}$ of heterogenous mass was found and the contours of the uterus was not clearly visualized. Patient was diagnosed as myoma protruding to vagina and was prepared for surgery. The plan was to remove the myoma from vaginal approach. Patient was prepared for operation in lithotomy position. The resection was performed till the root of the myoma but cervix uteri was not

\footnotetext{
${ }^{1}$ Department of Obstetrics and Gynecology Marmara University, Istanbul, Turkey

Address of Correspondence: Mehmet Vural

Department of Obstetrics and

Gynecology Marmara University,

Istanbul, Turkey

drmvural@yahoo.com

Submitted for Publication:

31. 07.2014

Accepted for Publication:

04. 11. 2014
}

visualized. It was considered as the inversion of the uterus. The pfannenstiel incision was performed. In the exploration, the fundus of the uterus was not seen. It was palpated with the tip of the finger $10 \mathrm{~cm}$ deep in the pelvis and adnexa were not visualized. Hysterectomy was performed. Figure 1 shows inverted uterus after hysterectomy. Patient had no complications in postoperative period and after restoration of the bowel and bladder functions she was discharged from hospital on the third day of surgery.

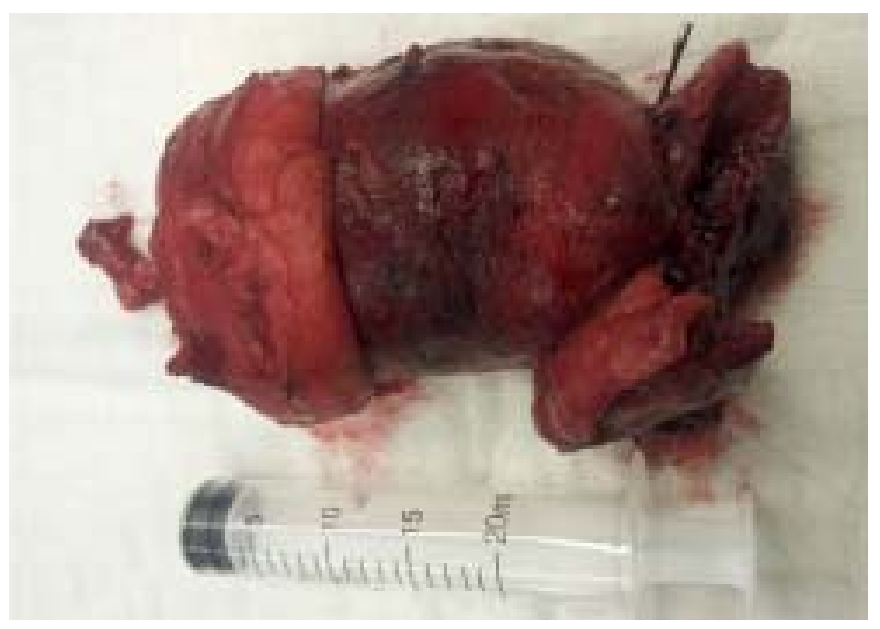

Figure 1: Inverted uterus after hysterectomy

\section{Discussion}

Post-partum uterine inversion with an estimated incidence of 1 in 30,000 deliveries is an infrequent complication of parturition. ${ }^{4}$ Non-puerperal uterine inversion is a rare condition, but the incidence is not accurately estimated and is mostly associated with a polypoid uterine mass such as benign leiomyomas. The remaining cases of tumor-related inversion are uterine sarcomas. Inversion associated with carcinoma is extremely rare..$^{5}$ Non puerperal uterine inversion in patients younger than 45 years old is uncommon and generally it is caused by malignant lesions. Carcinomas and sarcomas of the 
uterus are associated with those cases. One case of immature teratoma of the uterus causing uterine inversion was also reported $^{6}$ Only one case of 19 year old women with submucuosal myoma causing uterine inversion was reported by De Viries and Perquin. ${ }^{7}$

Vaginal bleeding, mass protruding through the introitus, lower abdominal pain, and urinary problems may be the symptoms of uterine inversion. ${ }^{8}$ The treatment of uterine inversion may be done according to the reproductive desire of the patient by reposition procedures or hysterectomy. ${ }^{9}$ Herein a case of non puerperal uterine inversion caused by a myoma protruding to vagina was described. Similar with the mechanism of intestinal intussusception, uterine contractions for expulsion of the mass caused by distention of the uterus may lead to uterin inversion. Patients presenting with vaginal bleeding and mass protruding through vagina may be candidate for uterine inversion. In these cases uterin inversion should be considered and urgent treatment strategies should be planned.

\section{References}

1. Buyukkrut S, Vardar MA, Zeren H, et al. Nonpuerperal inversion of uterus caused by leiomyosarcoma: a case report and clinical management. J Obstet Gynecol Res 2007;33: 402-6.

2. Lascarides E, Cohen M. Surgical management of non- puerperal inversion of the uterus. Obstet Gynecol 1968; 32:376-381.

3. Schulman JM, Stanton JS. Acute nonpuerperal uterine inversion. South Med J 1981;74:1142-5.

4. Das P. Inversion of the uterus. J Obstet Gynaecol Br Emp 1940;47:525-48.

5. Lupovitch A1, England ER, Chen R. Non-puerperal uterine inversion in association with uterine sarcoma: case report in a 26-year-old and review of the literature. Gynecol Oncol 2005;97(3):938-41.

6. Souza KT, Negrão MV, da Silva Rocha LS, Di Favero G, da Costa SC, Diz Mdel P. Immature uterine teratoma associated with uterine inversion. Rare Tumors 2014;6(3): 5530. doi: $10.4081 / \mathrm{rt} .2014$.

7. de Vr1ies M1, Perquin DA. Non-puerperal uterine inversion due to submucous myoma in a young woman: a case report. J Med Case Rep. 2010;4:21. doi:10.1186/17521947-4-21.

8. Ranjana T, Sebanti G, Chakravorty PS. Non puerperal uterine inversion. The Journal of Obstetrics and Gynecology of India 2012;62(4):452-3.

9. Atalay MA, Demir BÇ, Solak N, Atalay FO, Küçük kömürcü S. An unusual presentation of a submucous leiomyoma accounting to a non-puerperal uterine inversion: A case report. J Turk Ger Gynecol Assoc 2013;14(2):116-8. 